\title{
Label-free, microfluidic separation and enrichment of human breast cancer cells by adhesion difference $\dagger$
}

\author{
Keon Woo Kwon, ${ }^{a}$ Sung Sik Choi, ${ }^{b}$ Sang Ho Lee, ${ }^{b}$ Byungkyu Kim, ${ }^{c}$ Se Na Lee, ${ }^{b}$ Min Cheol Park, ${ }^{a}$ \\ Pilnam Kim, ${ }^{a}$ Se Yon Hwang ${ }^{a}$ and Kahp Y. Suh*a
}

\author{
Received 3rd July 2007, Accepted 9th July 2007 \\ First published as an Advance Article on the web 1st August 2007 \\ DOI: $10.1039 / \mathrm{b} 710054 \mathrm{j}$
}

\begin{abstract}
A label-free microfluidic method for separation and enrichment of human breast cancer cells is presented using cell adhesion as a physical marker. To maximize the adhesion difference between normal epithelial and cancer cells, flat or nanostructured polymer surfaces (400 nm pillars, $400 \mathrm{~nm}$ perpendicular, or $400 \mathrm{~nm}$ parallel lines) were constructed on the bottom of polydimethylsiloxane (PDMS) microfluidic channels in a parallel fashion using a UV-assisted capillary moulding technique. The adhesion of human breast epithelial cells (MCF10A) and cancer cells (MCF7) on each channel was independently measured based on detachment assays where the adherent cells were counted with increasing flow rate after a pre-culture for a period of time (e.g., one, two, and four hours). It was found that MCF10A cells showed higher adhesion than MCF7 cells regardless of culture time and surface nanotopography at all flow rates, resulting in label-free separation and enrichment of cancer cells. For the cell types used in our study, an optimum separation was found for 2 hours pre-culture on the $400 \mathrm{~nm}$ perpendicular line pattern followed by flow-induced detachment at a flow rate of $200 \mu \mathrm{min}^{-1}$. The fraction of MCF7 cells was increased from $0.36 \pm 0.04$ to $0.83 \pm 0.04$ under these optimized conditions.
\end{abstract}

\section{Introduction}

The separation and enrichment of cancer cells from a mixed phase of cancer and normal cells are the fundamental steps of diagnosis and further biological analysis of cancer. Current methods for detecting and separating cancer cells rely on observing morphological features or labeling with specific biomarkers. ${ }^{1-5}$ Use of a biomarker is highly specific and accurate but requires laborious, time-consuming preparation for staining prior to separation, and a post process such as removal of labeling. Also, a limited number of effective biomarkers (e.g., aptamers ${ }^{6}$ ) have been reported for cancer probing and diagnosis. Most widely used labeling-assisted methods are fluorescence activated cell sorting (FACS) and magnetic activated cell sorting (MACS) because of their high separation speed and specificity. ${ }^{7}$ These cell sorting systems have been miniaturized to microfluidic devices, demonstrating the possibility of being integrated into lab-on-a-chip devices. ${ }^{8,9}$

In contrast, label-free methods typically utilize differences in physical properties such as cell size, ${ }^{10}$ density, ${ }^{11}$ cell

\footnotetext{
${ }^{a}$ School of Mechanical and Aerospace Engineering, Seoul National University, Seoul, Korea.E-mail:sky4u@snu.ac.kr

${ }^{b}$ School of Life Sciences and Biotechnology, Korea University, Seoul, Korea

${ }^{c}$ School of Aerospace and Mechanical Engineering, Hankuk Aviation University, Kyonggi-Do, Korea

$\uparrow$ Electronic supplementary information (ESI) available: Test of viability of the detached MCF7 cells (Fig. S1) and two short movie clips showing detachment of the adhered MCF7 cells at a flow rate of $100 \mu \mathrm{min}^{-1}$ on the 400 pillar pattern (movie 1) and that of adhered MCF10A cells on the same pattern at a flow rate of $200 \mu 1 \mathrm{~min}^{-1}$ (movie 2). Both cell lines were pre-cultured for 2 hours prior to detachment assays. See DOI: 10.1039/b710054j
}

adhesion, ${ }^{12-15}$ and dielectric properties. ${ }^{16-18}$ One potential drawback in label-free methods is that the physical difference is not high enough for efficient separation in many cases, which limits the widespread use of the label-free methods. Nonetheless, the efficiency of separation could be enhanced under controlled micro/nanoenvironments by amplifying the physical differences.

Cell adhesion is one of the physical markers that can be used to detect and separate cells of interest. Currently, most cell separation and enrichment methods such as cell affinity chromatography (CAC) utilize immunoreactions to enhance the adhesion of one cell type than those of the other cell types. ${ }^{12-15}$ It is noted in this regard that the cell adhesion is also modified on a nanostructured surface without specific proteins; it could be increased or decreased depending on the material and geometry used to construct the surface structure. ${ }^{19-21}$ Recently, extensive efforts have been made to understand/control cell adhesions on various surface nanostructures using conventional or unconventional lithographic techniques. $^{22-25}$

A microfluidic system is advantageous for analysis of cell adhesion in various aspects because of small sample consumption, use of multiple parameters, and generation of large shear stress. $^{26,27}$ By integrating nanostructured surfaces with a microfluidic system, we herein devise a simple, label-free cell separation and enrichment scheme based on standard soft lithography and microfluidics protocol. The PDMS microfluidic device consists of four branch channels, each of which contains flat or polymeric nanostructures on the bottom (400 nm pillars, $400 \mathrm{~nm}$ perpendicular, and $400 \mathrm{~nm}$ parallel lines, respectively) to increase the difference in cell adhesion. Subsequently, the cells bound to the floor of a microfluidic 
channel were detached and the adhered cells were counted with increasing flow rate of medium in a stepwise fashion. As a consequence, an optimum condition for efficient separation and enrichment of cancer cells was established for the cell types used in this study, which is described below.

\section{Methods and materials}

\section{Fabrication of PUA mould}

The ultraviolet (UV)-curable polyurethane acrylate (PUA) mould material consists of a functionalized precursor with an acrylate group for cross-linking, a monomeric modulator, a photoinitiator and a radiation-curable releasing agent for surface activity. Details of the synthesis and characterization of the material have been published elsewhere. ${ }^{28}$ To fabricate a sheet-type mould, the liquid precursor was drop-dispensed onto a silicon master and then a flexible, transparent polyethylene terephthalate (PET) film was brought into contact with the precursor surface. Subsequently, the mould was exposed to UV light $(\lambda=200-400 \mathrm{~nm})$ for $20 \mathrm{~s}$ through the transparent backplane $\left(\right.$ dose $\left.=100 \mathrm{~mJ} \mathrm{~cm}^{-2}\right)$. After $\mathrm{UV}$ curing, the mould was peeled off from the master and additionally cured overnight to terminate the remaining active acrylate groups prior to use as a first replica. The resulting PUA mould used in the experiment was a thin sheet with a thickness of $\sim 50 \mu \mathrm{m}$.

\section{Fabrication of microfluidic channel with PUA nanopatterned substrate}

Glass substrate was rinsed with isopropyl alcohol (IPA) in an ultrasonic bath for $30 \mathrm{~min}$ and washed in a flow of distilled water and dried in a stream of nitrogen. Three types of nanostructures were fabricated onto glass substrate using UVassisted capillary moulding as shown in Fig. 1(a). ${ }^{29-31} \mathrm{~A}$ small amount of the PUA precursor $(\sim 0.1-0.5 \mathrm{~mL})$ was dropdispensed on the substrate and a first-replicated PUA mould (same material but without active acrylate groups) was directly placed onto the surface. The PUA precursor spontaneously moved into the cavity of the mould by means of capillary action and was cured by exposure to UV for $\sim 20 \mathrm{~s}$. After curing, the mould was peeled off from the substrate using a sharp tweezer. To increase the adhesion at the PUA nanostructure/glass interface, an adhesion promoter (phosphoric acrylate: propylene glycol monomethyl ether acetate $=$ $1: 10$, volume ratio) was coated onto glass substrate.

PDMS microfluidic moulds were fabricated by curing PDMS pre-polymer (Sylgard 184 Silicon elastomer, Dow Corning) on silicon masters prepared by photolithography. The masters used for microfluidic moulds had protruding (positive) features with the impression of the microfluidic channel. The microfluidic channel consists of four branch channels $(600 \mu \mathrm{m}$ in width and $50 \mu \mathrm{m}$ in height), which merged into two branches $(1200 \mu \mathrm{m}$ in width and $50 \mu \mathrm{m}$ in height $)$ and finally into one big channel $(2400 \mu \mathrm{m}$ in width and $50 \mu \mathrm{m}$ in height) that was connected to a syringe pump (Fig. 1b). Rulers with $500 \mu \mathrm{m}$ spacing were included in the four branch channels to easily locate the cells. To cure the PDMS pre-polymer, a mixture of $10: 1$ silicon elastomer and the curing agent was poured on the master and cured at $70{ }^{\circ} \mathrm{C}$ for $1 \mathrm{~h}$. The PDMS replicas were then peeled from the silicon masters and cut prior to use. For the PDMS microfluidic moulds, holes were punched through the inlet and the outlet as a reservoir. For channel bonding, the PDMS microfluidic mould and glass substrate were treated in oxygen plasma for $60 \mathrm{~s}$ (60 W, PDC32G, Harrick Scientific, Ossining, NY). After plasma treatment, the channel mould was brought in conformal contact with the substrate with careful alignment and firmly pressed to form an irreversible seal. The device was heated on a hot plate for several tens of minutes to further strengthen the sealing.

\section{Scanning electron microscopy (SEM)}

High-resolution SEM images of PUA nanostructures and cell morphologies were obtained using a HITACHI S-4800 microscope (Hitachi, Japan) operating at an accelerating voltage of $5 \mathrm{kV}$. To avoid charging effects, substrates were sputter-coated with $\mathrm{Au}$ to a thickness of $20 \mathrm{~nm}$ prior to measurements.

\section{Cell culture and measurement of cell adhesion}

Both MCF10A and MCF7 cells were obtained from the American Type Culture Collection (ATCC). The human normal breast epithelial cell line, MCF10A, was cultured in DMEM/F-12 medium containing 5\% horse serum, $100 \mathrm{U} \mathrm{ml}^{-1}$ penicillin, $100 \mu \mathrm{g} \mathrm{ml}^{-1}$ streptomycin, $100 \mathrm{ng} \mathrm{ml}^{-1}$ cholera toxin, $10 \mathrm{ng} \mathrm{ml}^{-1}$ epidermal growth factor, $0.5 \mathrm{mg} \mathrm{ml}^{-1}$ hydrocortisone, $10 \mathrm{mg} \mathrm{ml}^{-1}$ insulin, and $1 \%$ (w/v) L-glutamine at $37{ }^{\circ} \mathrm{C}$ under an atmosphere of $5 \% \mathrm{CO}_{2}$ (all from Sigma Chemical, St Louis, MO). The human breast cancer cell line, MCF7, was similarly cultured in DMEM containing 10\% FBS, $100 \mathrm{U} \mathrm{ml}^{-1}$ penicillin, $100 \mu \mathrm{g} \mathrm{ml}^{-1}$ streptomycin, $10 \mathrm{mg} \mathrm{ml}^{-1}$ insulin, and $1 \%(\mathrm{w} / \mathrm{v}) \mathrm{L}$-glutamine. ${ }^{32}$ Both cells were grown at a concentration of $1.0 \times 10^{5} \mathrm{ml}^{-1}$ and sub-cultured when the cells were confluent at about $70 \%$. For cell culture in a microfluidic chamber, cells were harvested by treating with $0.025 \%$ trypsin-EDTA, washed three times to remove the trace of trypsin and incubated for $30 \mathrm{~min}$ before injection into the channel to stabilize cells. Cell density was controlled at $\sim 2.5 \times 10^{6} \mathrm{ml}^{-1}$ to provide consistent experimental conditions. When the mixed cells of MCF10A and MCF7 lines were used, the medium was made by mixing two different culture media at a ratio of $1: 1$.

To measure cell adhesion, each cell line was injected inside a microfluidic channel (coated with $0.1 \%(\mathrm{w} / \mathrm{v})$ gelatin) by surface tension driven capillary flow and the cells were left adhered to the floor of the channel in an incubator for different culture times of 1, 2 and $4 \mathrm{~h}$, respectively. Flat or PUA nanostructures (400 nm pillar, $400 \mathrm{~nm}$ perpendicular, and $400 \mathrm{~nm}$ parallel line patterns) were constructed on the bottom of four branch channels. To apply a uniform shear stress, cells were distributed uniformly with a sufficient spacing between adhered cells. After cell culture, the microfluidic channel was connected to a syringe pump and then the Hank's balanced salt solution (HBSS) was flowed into the channel with increasing flow rate in a stepwise manner. For each step, the medium was flowed for $1 \mathrm{~min}$ and the adherent cells were counted under an optical microscope (Nikon Eclipse TE2000, Tokyo, Japan). 
(a)
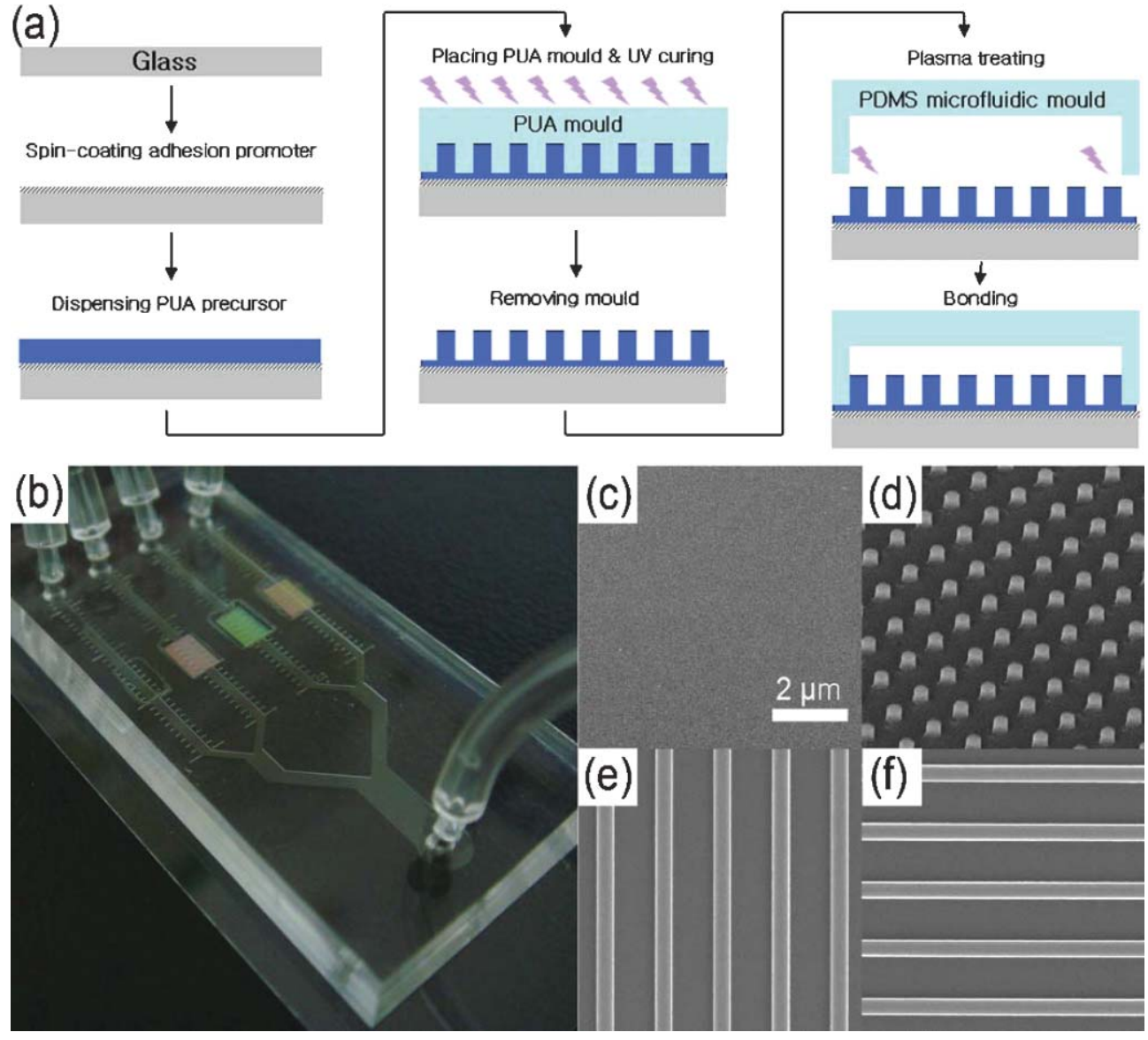

Fig. 1 (a) A schematic diagram for the fabrication of a microfluidic channel integrated with a nanopatterned substrate. Here, PUA nanostructures were fabricated using UV-assisted capillary moulding onto glass substrate and the patterned substrate was irreversibly bonded to the channel by treatment with oxygen plasma. (b) A photograph showing the fabricated microfluidic channel having four branch channels with patterned substrate (each branch channel is $600 \mu \mathrm{m}$ in width, $50 \mu \mathrm{m}$ in height, and the length is $15 \mathrm{~mm}$ ). In the figure, different diffraction colors represent different patterns. (c)-(f) SEM images of flat or three PUA nanostructures included inside a microfluidic channel: (c) PUA flat surface, (d) $400 \mathrm{~nm}$ pillars (e) $400 \mathrm{~nm}$ perpendicular lines, and (f) $400 \mathrm{~nm}$ parallel lines.

Separation and enrichment of human breast cancer cells (MCF7)

Approximately $30 \%$ of MCF7 cells were mixed with MCF10A cells at a total density of $\sim 2.5 \times 10^{6} \mathrm{ml}^{-1}$ as described above. To distinguish MCF7 and MCF10A cells, the nuclei of MCF7 cells were stained with $10 \mu \mathrm{g} \mathrm{ml}^{-1}$ Hoechst 33342 before mixing and both cell types were introduced inside a microfluidic channel having a patterned substrate with $400 \mathrm{~nm}$ perpendicular lines after culture for $2 \mathrm{~h}$. After the microfluidic device was installed in an optical microscope equipped with fluorescence filter blocks, the non-viable cells were initially washed by the HBSS at a flow rate of $10 \mu \mathrm{min}^{-1}$ for $1 \mathrm{~min}$ and the locations of MCF7 cells were recorded under the fluorescent microscope. Subsequently, the HBSS was flowed into the channel at a flow rate of $200 \mu \mathrm{min}^{-1}$ for $3 \mathrm{~min}$ and adherent cells were counted under the microscope.

\section{Results and discussion}

Integration of a microfluidic device with nanopatterned substrate

Fig. 1(c)-(f) shows SEM images of flat PUA and three types of PUA nanostructures that were included inside the four branch channels. As shown in the figure, the nanostructures were neatly formed over a large area without many defects (see different diffraction colors in Fig. 1(b)). Each patterned area was $0.6 \times 4 \mathrm{~mm}^{2}$. The geometric parameters of PUA nanostructures were: $400 \mathrm{~nm}$ pillars of $400 \mathrm{~nm}$ height, $1 \mu \mathrm{m}$ spacing, $400 \mathrm{~nm}$ perpendicular, and $400 \mathrm{~nm}$ parallel lines (with respect to the direction of flow) of $400 \mathrm{~nm}$ height, $1 \mu \mathrm{m}$ spacing, respectively. These patterns were carefully designed and fabricated such that the height and spacing were the same with different nanopatterns to minimize the effects of structure dimensions. Since the flow is fully developed (the entrance length is merely $0.368 \mu \mathrm{m}$ at $1200 \mu \mathrm{lmin}^{-1}$, which was the maximum flow rate in our experiment) and the height of the nanostructures was much smaller than the channel height, the hydrodynamic conditions for each channel can be assumed to be constant.

\section{Adhesions of MCF10A and MCF7 cells}

Difference in cell adhesion is a key parameter to enable separation and enrichment of cancer cells for the microfluidic approach presented here. According to recent studies, ${ }^{19-21}$ cell adhesions are significantly affected by surface chemical composition and nanotopography. More specifically, the cell 
adhesion could be increased or decreased depending on the material and geometry used to construct the surface structure. In this regard, the adhesion strength was evaluated for normal and cancer cells by increasing flow rate of the HBSS in a stepwise fashion. The step increase was adjusted to each cell line and flow rate, i.e., $50 \mu \mathrm{min}^{-1}$ for low flow rates and increased to $100 \mu \mathrm{min}^{-1}$ for high flow rates for MCF10A cells and $50 \mu \mathrm{min}^{-1}$ for MCF7 cells (fixed regardless of flow rate). The duration of each step was 1 min throughout the experiment.

In Fig. 2, the fraction of adherent cells was plotted for (a)(c) normal and (d)-(f) cancer cells as a function of flow rate for a given culture time. A number of notable findings were derived from the figure. First, the fraction of MCF10A cells was higher than that of MCF7 cells regardless of culture time and surface nanotopography at all flow rates. In particular, the fraction of MCF7 cells decreased drastically at a relatively low flow rate compared to that of MCF10A cells. Second, the fraction of MCF10A cells was much lower on glass and PUA flat substrate than that on nanopatterned substrate, suggesting that the PUA nanostructure could create a favorable environment for adhesion and spreading of MCF10A cells. Third, MCF7 cells were not sensitive to the patterned substrate as judged by a negligible difference in cell adhesion with different nanostructures. It is noted that the values in Fig. 2 were averaged over at least 3 repetitions using $80-100$ cells per each experiment, thus representing statistical significance.

Shown in Fig. 3 is the plot for the fractional difference of adherent cells as a function of culture time for the same flow rate of $200 \mu \mathrm{min}^{-1}$. With the exception of glass control the
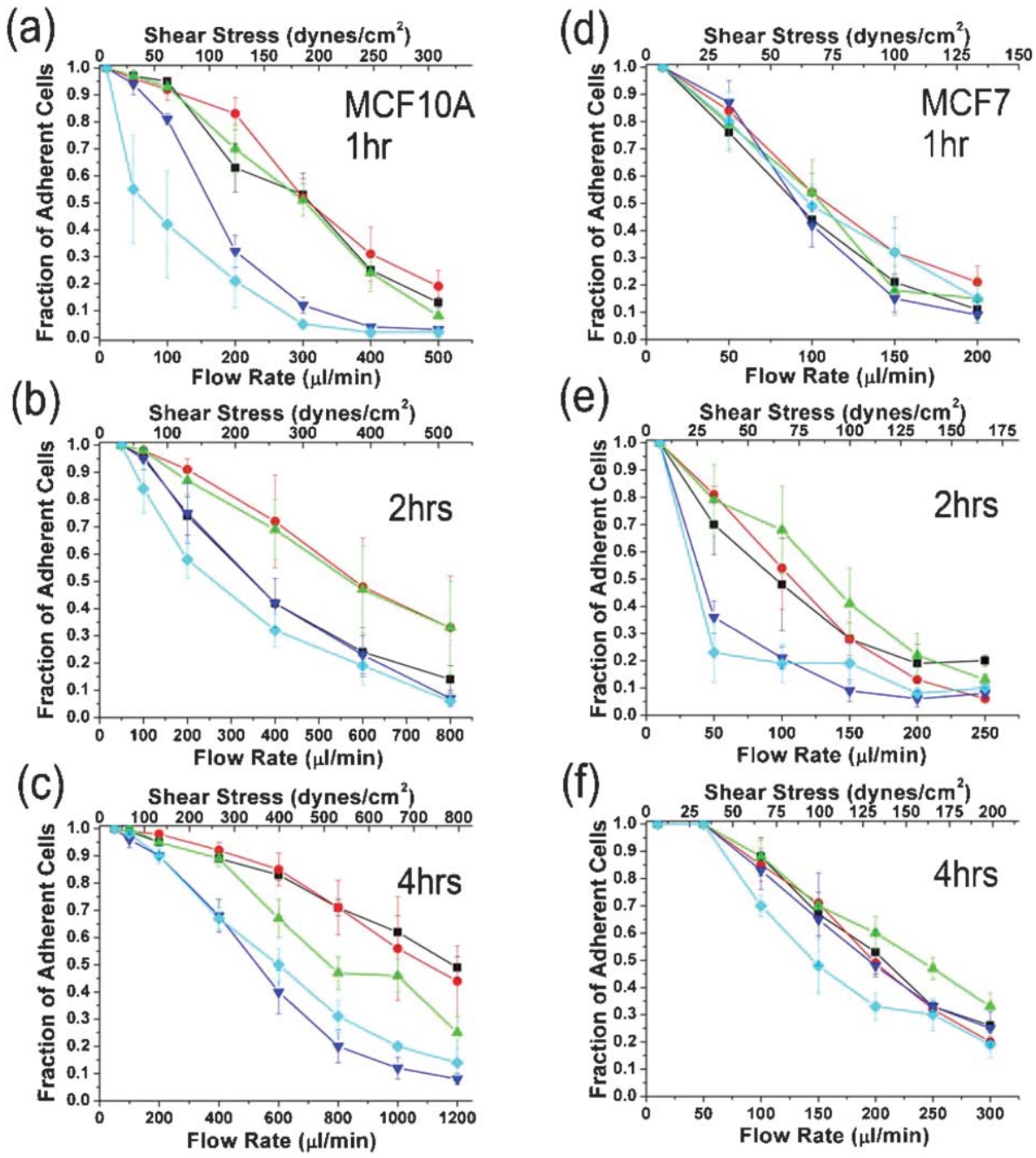

$$
\begin{aligned}
& \text { - 400nm Pillars } \\
& \text { - 400nm Perpendicular Lines } \\
& \text { - PUA Flat Surface } \\
& \text { - Glass }
\end{aligned}
$$

Fig. 2 (a)-(c) Fraction of the adhered MCF10A and (d)-(f) MCF7 cells: (a), (d) 1 h, (b), (e) 2 h, and (c), (f) 4 h culture, respectively. These values were averaged over 3 repetitions and error bars represent the standard errors of the mean (standard deviation $/ \sqrt{n}$, wheren $=3$ ). 


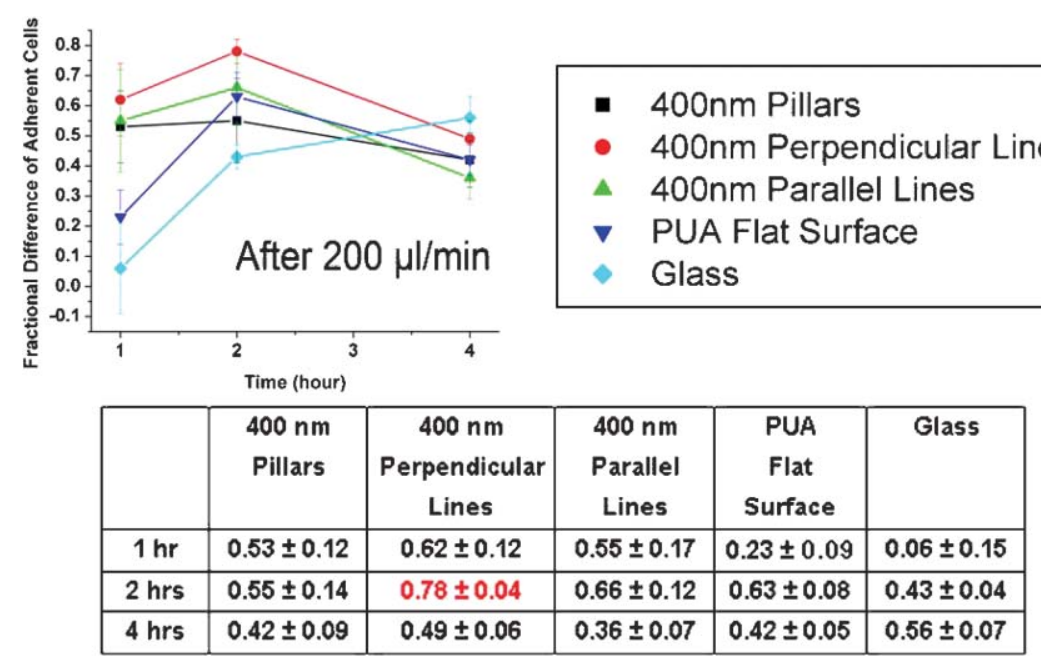

Fig. 3 Fractional difference between the adhered MCF10A and MCF7 cells after flowing HBSS at a flow rate of $200 \mu 1 \mathrm{~min}{ }^{-1}$ for 3 min. The maximum value of 0.78 was obtained on the $400 \mathrm{~nm}$ perpendicular line pattern after $2 \mathrm{~h}$ pre-culture. These values were averaged over 3 repetitions and error bars represent the standard errors of the mean (standard deviation $/ \sqrt{n}$, wheren $=3$ ).

fractional difference showed a peak around $2 \mathrm{~h}$ of culture and decreased as the culture time increased. This fact reveals that the adhesion strength of MCF7 as well as MCF10A cells increases with increasing culture time. On glass control, it seems that the cells are not able to recognize the surface within a short period of time $(1 \mathrm{~h})$. For all the conditions tested, $1 \mathrm{~h}$ culture was not sufficient for proper separation of cancer cells, indicating that MCF10A cells would not spread over the surface up to $1 \mathrm{~h}$. If the culture time is increased to $4 \mathrm{~h}$ with a higher flow rate of $400 \mu \mathrm{min}^{-1}$, the fractional difference could be as high as 0.84 (see Fig. 2). Such a long time culture, however, is not suitable for high speed cell analysis and this high flow rate can exert more shear damage to the adhered cells, thus compromising cell viability. Based on these observations, the optimum condition for separation and enrichment of MCF7 cells from a mixed phase of MCF7 and MCF10A cells could be given at a flow rate of $200 \mu 1 \mathrm{~min}^{-1}$ following $2 \mathrm{~h}$ culture on the perpendicular line pattern. Under these conditions, the maximum fractional difference was $0.78 \pm 0.04$. The reason why the perpendicular line pattern showed the best performance can be attributed to the largest shear stress generated on the cell surface than the other two patterns. This increased shear stress appears to facilitate detachment of MCF7 cells while suppressing detachment of MCF10A cells without compromising cell-substrate interactions.

\section{Morphology and hydrodynamic force of MCF10A and MCF7 cells}

Fig. 4 shows representative SEM images of (a)-(d) MCF10A and (e)-(h) MCF7 cells cultured for $2 \mathrm{~h}$ on various surfaces used in the experiment. As shown in the figure, the morphology of MCF10A cells on the $400 \mathrm{~nm}$ pillar pattern was flat with a spherical nucleus inside, similar to those on bare PUA and glass surfaces. Also, the morphology of MCF10A cells on the $400 \mathrm{~nm}$ line pattern showed contact guidance along the line direction presumably with more clusters of focal adhesions at the leading edges, corresponding to earlier results. ${ }^{22}$ By contrast, MCF7 cells showed starshaped morphology (typical characteristics of cancer cell) on the $400 \mathrm{~nm}$ pillar and line patterns. It is noted that the elongation of MCF7 cells was not pronounced on the line pattern compared to MCF10A cells, suggesting that the adhesion of cancer cells would be relatively weak. For cell spreading, lamellipodia of MCF10A cells spread widely on the surfaces regardless of the material and geometry and partially migrated to the bottom of the substrate between nanostructures. By contrast, lamellipodia of MCF7 cells stretched radially on the pillar pattern whereas those on the line pattern showed more irregular and asymmetric shapes. Based on these observations, the adhesion strength of MCF7 cells would be much lower than that of MCF10A cells.

In order to examine whether the observed differences in the flow rate that are required to remove cells from surfaces are due to a difference in cell adhesion, not to the other factors, it would be beneficial to calculate hydrodynamic force $\left(F_{\mathrm{H}}\right)$ that is applied to the adherent cell surfaces. $F_{\mathrm{H}}$ is related to the adhesive force $\left(F_{\mathrm{A}}\right)$, which might be equal to $F_{\mathrm{H}}$ when $50 \%$ of the adherent cells detach from the cultured surfaces. ${ }^{33}$ According to a previous study, ${ }^{34} F_{\mathrm{H}}$ can be given by the summation of two components of hydrodynamic shear force and torque. Additionally, $F_{\mathrm{H}}$ should be modified as a function of the ratio of cell to channel height $(\gamma)$ in a microchannel geometry $^{35}$ and needs to be implemented with shape evolution during cell spreading. ${ }^{36}$ For the cell shape elongated on the $400 \mathrm{~nm}$ line pattern as shown in Fig. 4(b), (f) with small $\gamma$ $(<0.25), F_{\mathrm{H}}$ is given by the following form after algebraic manipulation:

$$
F_{\mathrm{H}}=\tau_{\text {avg }} A_{\text {surf }} \sqrt{1+\left(\frac{c}{b}\right)^{2}} \cong 6 \sqrt{c^{2}+a^{2}} b \tau_{\text {wall }} \sqrt{1+\left(\frac{c}{b}\right)^{2}}
$$

where $\tau_{\text {avg }}$ is the average shear stress, $A_{\text {surf }}$ is the cell surface area, $\tau_{\text {wall }}$ the wall shear stress, and $a, b$, and $c$ are the length, width, and height of the adhered cell, respectively. The 


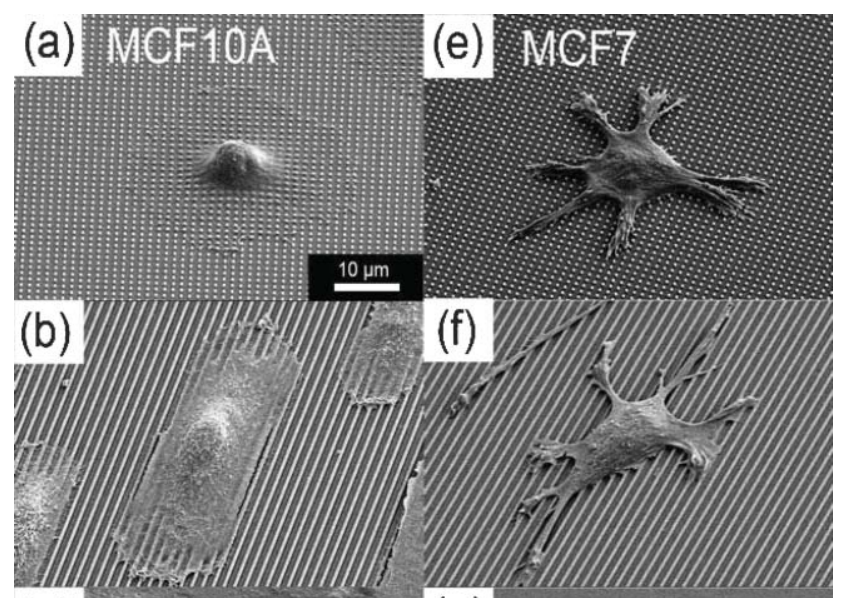

(c)
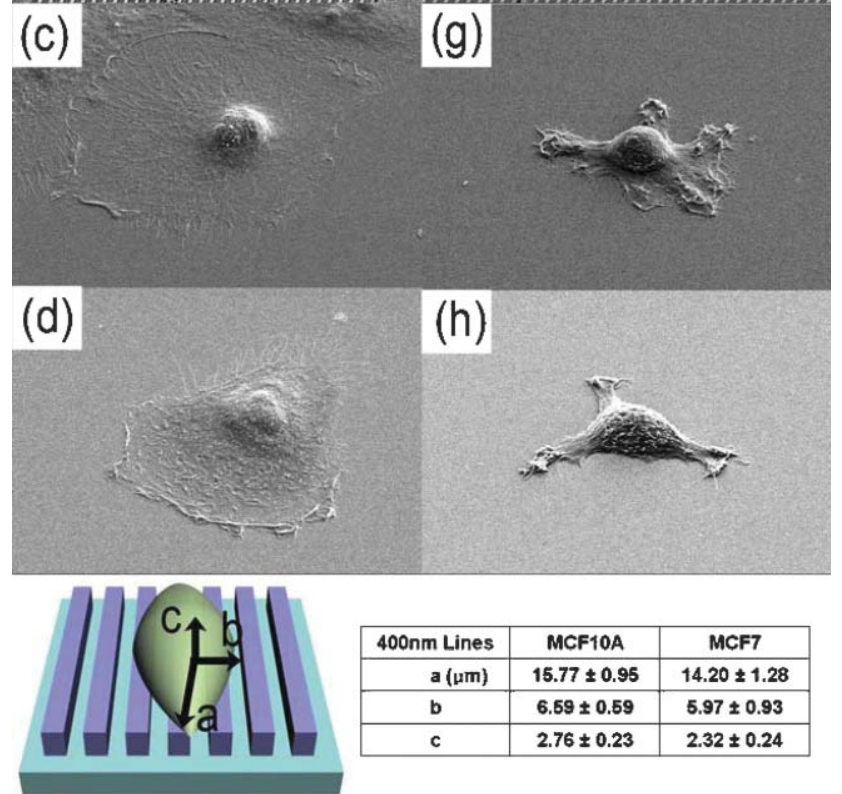

Fig. 4 SEM images of (a)-(d) MCF10A and (e)-(h) MCF7 cells on three different PUA nanostructures, PUA flat surface, and glass control after $2 \mathrm{~h}$ pre-culture: (a), (e) $400 \mathrm{~nm}$ pillars, (b), (f) $400 \mathrm{~nm}$ lines, (c), (g) PUA flat surface, and (d), (h) glass control. On the bottom, the parameters of cell size are shown along with the definition. These values were averaged over 18 repetitions and error bars represent the standard errors of the mean (standard deviation/ $\sqrt{n}$, wheren $=18$ ).

geometrical parameters of the adhered cell were measured from the SEM images in Fig. 4 and given on the bottom along with the graphical definition. Here, $\tau_{\text {wall }}$ is given by

$$
\tau=\frac{3 \mu Q}{2 h^{2} w}
$$

where $Q$ is the volumetric flow rate, $h$ is the half the channel height, $w$ is the channel width, and $\mu$ is the fluid viscosity. In deriving eqn (1), it was assumed that $\tau_{\text {avg }}=\tau_{\max } / 2$ where $\tau_{\max }=$ $3 \tau_{\text {wall }} \cdot{ }^{35}$ Accordingly, the hydrodynamic forces were calculated to be $9.15 \mathrm{nN}$ and $7.37 \mathrm{nN}$ for MCF10A and MCF7 cells, respectively. This result demonstrated that the detachment of MCF7 cells is mediated by weak adhesions to the substrate since the hydrodynamic force applied to the cancer cell surface is smaller.
Separation and enrichment of MCF7 cells from a mixed phase of MCF10A and MCF7 cells

To demonstrate potential applications to label-free separation and enrichment of cancer cells, a simple separation scheme is presented here. As shown in Fig. 5, the fraction of adherent MCF7 cells to the total adherent cells was $0.36 \pm 0.04$ prior to flow-induced detachment. After flowing the HBSS under optimized conditions (flow rate of $200 \mu \mathrm{min}^{-1}$ for $3 \mathrm{~min}$ ), the fraction of detached MCF7 cells to the total detached cells was increased to $0.83 \pm 0.04 \mu \mathrm{min}^{-1}$, indicating that the cancer cells can be readily separated and enriched by utilizing the difference in cell adhesion. These values were averaged over 13 independent experiments using $\sim 1000$ cells in total, thus representing statistical significance. To check the damage on cells caused by this removal process, viability of the

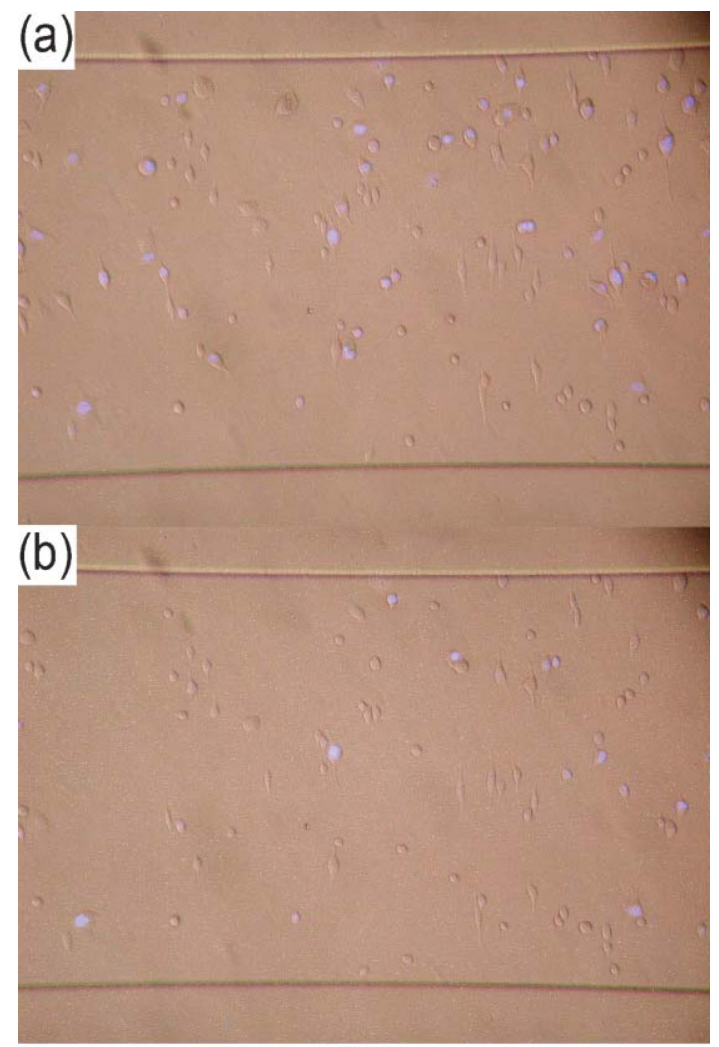

\begin{tabular}{|c|c|}
\hline Adherent MCF7 & Detached MCF7 \\
\hline Adherent MCF7 + MCF10A & Detached MCF7 + MCF10A \\
\hline $0.36 \pm 0.04$ & $0.83 \pm 0.04$ \\
\hline
\end{tabular}

Fig. 5 Separation of MCF7 cells from a mixed phase of MCF10A and MCF7 cells (MCF7 30\%) under optimized conditions ( $2 \mathrm{~h}$ preculture on the $400 \mathrm{~nm}$ perpendicular line pattern followed by detachment at a flow rate of $200 \mu \mathrm{min}^{-1}$ for $3 \mathrm{~min}$ ): (a) A merger of the bright-field image after flowing HBSS at $10 \mu \mathrm{min}^{-1}$ for $1 \mathrm{~min}$ and the corresponding florescence image. (b) A merger of bright-field image of the same channel after flowing HBSS at $200 \mu \mathrm{min}^{-1}$ for $3 \mathrm{~min}$ and the corresponding florescence image. The nucleus of MCF7 cells was stained with Hoechst 33342. On the bottom, the fraction of initial MCF7 cells to the total adherent cells and of the detached MCF7 cells to the total detached cells is shown. These values were averaged over 13 repetitions and error bars represent the standard errors of the mean (standard deviation $/ \sqrt{n}$, wheren $=13$ ). 
detached MCF7 cells was tested. In this experiment, the MCF7 cells were cultured on the $400 \mathrm{~nm}$ perpendicular line pattern for $2 \mathrm{~h}$ and detached under the same conditions. It was found that the percentage of viable cells was $>95 \%$ (see ESI $\dagger$ ).

\section{Potential limitations and challenges}

The separation efficiency in our method turned out to be as high as that of other affinity-based cell separation methods $(\sim 0.8)$ including cell affinity chromatography $(\mathrm{CAC}){ }^{12-15} \mathrm{It}$ seems that the efficiency could be further enhanced by better control over surface nanotopography and patterned material properties and by better understanding of cell-substrate interactions. In addition to this labeling free characteristic, our method is an intrinsically parallel process such that it takes merely $3 \mathrm{~min}$ to separate and enrich MCF7 cells from a mixture while recognizing the fact that a pre-culture step is required for several hours. This feature is contrasted with sequential DEP and FACS systems in that cells are separated one by one. Also, an increase in throughput can be readily implemented by multiplying channel number or by increasing channel length.

Our method also poses a number of potential limitations and challenges. First, the laminar flow inside a microfluidic channel would represent different velocities at different locations, thus preventing cell detachment at the edge of the channel even at a high flow rate. A recent study demonstrated that $90 \%$ of the channel except for edges $(10 \%)$ showed similar flow velocity in a laminarly flowing stream. ${ }^{26}$ This is also supported by our experimental finding in Fig. 5 in which the remaining MCF7 cells were evenly distributed over the entire channel, not limited to the edge region. Although the cells located at the edges still pose a potential problem, a simple hydrodynamic focusing set-up would solve this challenge. Second, it was found that the fraction of remaining MCF7 cells was increased when both cell lines were mixed and incubated together inside the microchannel. For example, the fraction of MCF7 cells after detachment assay was $0.13 \pm 0.04$ in the absence of MCF10A cells, which was increased to $0.23 \pm$ 0.07 in the presence of MCF10A cells. It appears that some factors including epidermal growth factor in the medium of MCF10A cells enhance the adhesion of MCF7 cells. Third, the separation efficiency is currently $78 \%$, which is not sufficient for accurate functioning of the device. Although the diversity in cell size and cell-surface interactions would be difficult to control, the efficiency could be further improved by a modified cell culture protocol or geometry of the microfluidic channel.

\section{Conclusions}

We have presented a simple microfluidic device for label-free separation and enrichment of cancer cells using difference in cell adhesion as a physical index. Our results demonstrated that the adhesion strength of MCF10A cells is higher than that of MCF7 cells regardless of pre-culture time and surface nanotopography at all flow rates. Also, the fractional difference between the adhered MCF10A and MCF7 cells varied with pre-culture time and showed a maximum around 2 hours with the exception of glass control. Of the patterns tested, the $400 \mathrm{~nm}$ perpendicular line pattern exhibited the best performance under the optimum conditions of 2 hours culture at a flow rate of $200 \mu \mathrm{l} \mathrm{min}{ }^{-1}$ for $3 \mathrm{~min}$. In a simple experimental scheme of enriching cancer cells, the fraction of MCF7 cells was increased from $0.36 \pm 0.04$ to $0.83 \pm 0.04$. The cell viability was also checked for the detached MCF7 cells, revealing that most of the cells were viable $(>95 \%)$. It is hoped that this microfluidic device could serve as an alternative for separation and enrichment of cancer cells with a minimal volume of body fluid containing a mixed population of normal and cancer cells. A future study would be directed towards analyzing the captured cancer cells for drug screening or other biological studies.

\section{Acknowledgements}

This work was supported by the Ministry of Science and Technology through Bio Tool R\&D Project for Cell Research and in part by the Micro Thermal System Research Center of Seoul National University.

\section{References}

1 A. M. Moriarty, H. Alexander, R. A. Lerner and G. B. Thornton, Science, 1985, 227, 429-433.

2 I. Tamm, I. Cardinale, T. Kikuchi and J. G. Krueger, Proc. Natl. Acad. Sci. U. S. A., 1994, 91, 4338-4342.

3 N. Scholler, N. Fu, Y. Yang, Z. M. Ye, G. E. Goodman, K. E. Hellstrom and I. Hellstrom, Proc. Natl. Acad. Sci. U. S. A., 1999, 96, 11531-11536.

4 J. H. Kim, J. S. Kim, H. Choi, S. M. Lee, B. H. Jun, K. N. Yu, E. Kuk, Y. K. Kim, D. H. Jeong, M. H. Cho and Y. S. Lee, Anal. Chem., 2006, 78, 6967-6973.

5 J. K. Herr, J. E. Smith, C. D. Medley, D. H. Shangguan and W. H. Tan, Anal. Chem., 2006, 78, 2918-2924.

6 D. Shangguan, Y. Li, Z. W. Tang, Z. H. C. Cao, H. W. Chen, P. Mallikaratchy, K. Sefah, C. Y. J. Yang and W. H. Tan, Proc. Natl. Acad. Sci. U. S. A., 2006, 103, 11838-11843.

7 A. Lostumbo, D. Mehta, S. Setty and R. Nunez, Exp. Mol. Pathol., 2006, 80, 46-53.

8 M. Berger, J. Castelino, R. Huang, M. Shah and R. H. Austin, Electrophoresis, 2001, 22, 3883-3892.

9 M. M. Wang, E. Tu, D. E. Raymond, J. M. Yang, H. C. Zhang, N. Hagen, B. Dees, E. M. Mercer, A. H. Forster, I. Kariv, P. J. Marchand and W. F. Butler, Nat. Biotechnol., 2005, 23, 83-87.

10 A. Higuchi and Y. Tsukamoto, J. Biomed. Mater. Res., Part A, 2004, 71A, 470-479

11 Y. Ito and K. Shinomiya, J. Clin. Apher., 2001, 16, 186-191.

12 Z. Du, N. Colls, K. H. Cheng, M. W. Vaughn and L. Gollahon, Biosens. Bioelectron., 2006, 21, 1991-1995.

13 W. C. Chang, L. P. Lee and D. Liepmann, Lab Chip, 2005, 5, 64-73.

14 A. Sin, S. K. Murthy, A. Revzin, R. G. Tompkins and M. Toner, Biotechnol. Bioeng., 2005, 91, 816-826.

15 B. D. Plouffe, D. N. Njoka, J. Harris, J. H. Liao, N. K. Horick, M. Radisic and S. Murthy, Langmuir, 2007, 23, 5050-5055.

16 F. F. Becker, X. B. Wang, Y. Huang, R. Pethig, J. Vykoukal and P. R. C. Gascoyne, Proc. Natl. Acad. Sci. U. S. A., 1995, 92, $860-864$.

17 Y. Huang, S. Joo, M. Duhon, M. Heller, B. Wallace and X. Xu, Anal. Chem., 2002, 74, 3362-3371.

18 C. M. Das, F. Becker, S. Vernon, J. Noshari, C. Joyce and P. R. C. Gascoyne, Anal. Chem., 2005, 77, 2708-2719.

19 J. Y. Lim, J. C. Hansen, C. A. Siedlecki, J. Runt and H. J. Donahue, J. R. Soc. Interface, 2005, 2, 97-108.

20 N. Sniadecki, R. A. Desai, S. A. Ruiz and C. S. Chen, Ann. Biomed. Eng., 2006, 34, 59-74.

21 A. S. G. Curtis, B. Casey, J. O. Gallagher, D. Pasqui, M. A. Wood and C. D. Wilkinson, Biophys. Chem., 2001, 94, 275-283.

22 A. I. Teixeira, G. A. Abrams, P. J. Bertics, C. J. Murphy and P. F. Nealey, J. Cell Sci., 2003, 116, 1881-1892. 
23 R. Carbone, I. Marangi, A. Zanardi, L. Giorgetti, E. Chierici, G. Berlanda, A. Podesta, F. Fiorentini, G. Bongiorno, P. Piseri, P. G. Pelicci and P. Milani, Biomaterials, 2006, 27, 3221-3229.

24 D. H. Kim, P. Kim, I. Song, J. M. Cha, S. H. Lee, B. Kim and K. Y. Suh, Langmuir, 2006, 22, 5419-5426.

25 J. Norman and T. Desai, Ann. Biomed. Eng., 2006, 34, 89-101.

26 H. Lu, L. Y. Koo, W. C. M. Wang, D. A. Lauffenburger, L. G. Griffith and K. F. Jensen, Anal. Chem., 2004, 76, 5257-5264.

27 E. Martines, K. McGhee, C. Wilkinson and A. Curtis, IEEE Trans. Nanobiosci., 2004, 3, 90-95.

28 S. J. Choi, P. J. Yoo, S. J. Baek, T. W. Kim and H. H. Lee, J. Am. Chem. Soc., 2004, 126, 7744-7745.

29 K. Y. Suh, Y. S. Kim and H. H. Lee, Adv. Mater., 2001, 13, $1386-1389$.
30 A. Khademhosseini, K. Y. Suh, S. Jon, G. Eng, J. Yeh, G. J. Chen and R. Langer, Anal. Chem., 2004, 76, 3675-3681.

31 M. C. Park, J. Y. Hur, K. W. Kwon, S. H. Park and K. Y. Suh, Lab Chip, 2006, 6, 988-994.

32 J. H. Chen, J. A. Bander, T. A. Santore, Y. B. Chen, P. T. Ram, M. J. Smit and R. Iyengar, Proc. Natl. Acad. Sci. U. S. A., 1998, 95, 2648-2652.

33 S. P. Wankhede, Z. Q. Du, J. M. Berg, M. W. Vaughn, T. Dallas, K. H. Cheng and L. Gollahon, Biotechnol. Prog., 2006, 22, 1426-1433.

34 D. A. Hammer and D. A. Lauffenburger, Biophys. J., 1987, 52, 475-487.

35 D. P. Gaver and S. M. Kute, Biophys. J., 1998, 75, 721-733.

36 L. A. Olivier and G. A. Truskey, Biotechnol. Bioeng., 1993, 42, 963-973.

\section{Textbooks from the RSC}

The RSC publishes a wide selection of textbooks for chemical science students. From the bestselling Crime Scene to Court, 2nd edition to groundbreaking books such as Nanochemistry: A Chemical Approach to Nanomaterials, to primers on individual topics from our successful Tutorial Chemistry Texts series, we can cater for all of your study needs.

Find out more at www.rsc.org/books Lecturers can request inspection copies - please contact sales@rsc.org for further information.

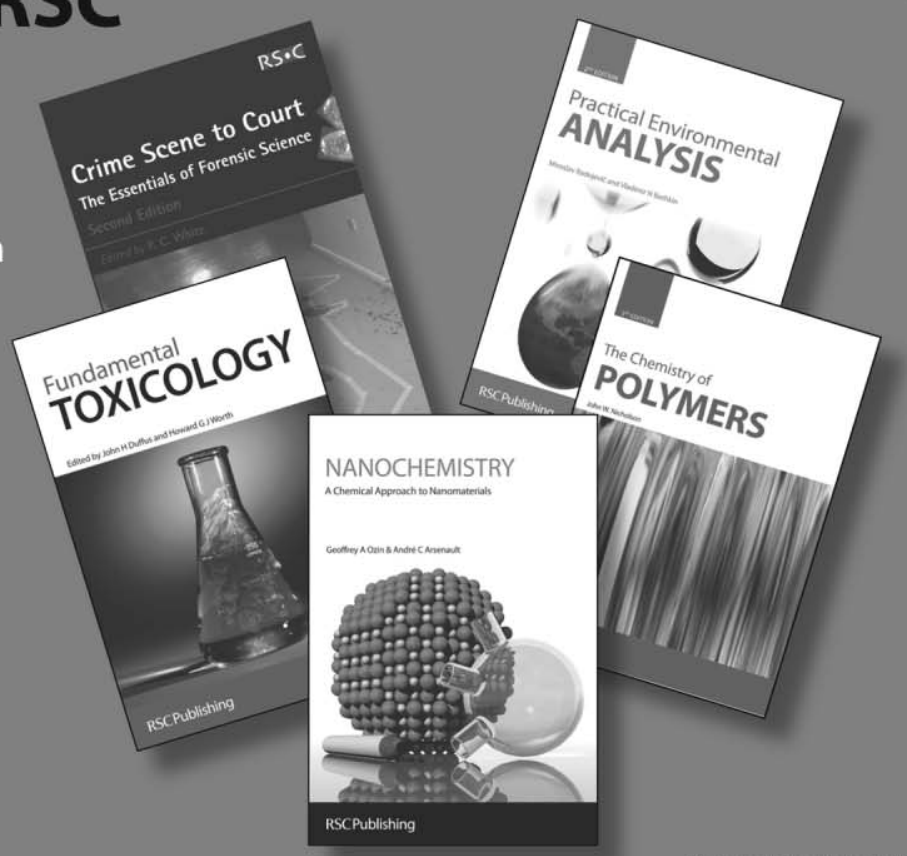

\section{RSCPublishing}

